\title{
Anestesia para Miastenia Gravis
}

\author{
Anaesthesia in Miastenia gravis
}

José Luiz Gomes do Amaral

Professor Titular, Disciplina de Anestesiologia, Dor e Terapia Intensiva Cirúrgica, Escola Paulista de Medicina / Universidade Federal de São Paulo - UNIFESP.

\section{Definição}

A miastenia gravis (MG) é doença auto-imune determinada pela ligação de autoanticorpos às sub-unidades alfa dos receptores de acetilcolina (nAchRs) na junção neuromuscular.

\section{Patologia}

Observa-se nos portadores de MG redução (a aproximadamente 30\% do normal) da densidade de nAchRs na placa mioneural secundária à ligação com auto-anticorpos e perda das dobras (lise focal) das membranas celulares devida a fixação de complemento.

Cerca de $80 \%$ dos pacientes com MG têm anticorpos circulantes contra acetilcolina (soropositivos). Em 70\% dos soronegativos encontram-se anticorpos contra o receptor tirosina-cinase (MuSK) específico do músculo esquelético.

Em 70\% dos casos de MG observa-se hiperplasia folicular linfóide do timo, cujos centros germinativos produzem anticorpos contra nAchRs. Observa-se timoma entre $10 \%$ e $15 \%$ dos casos e hiperplasia tímica na maioria dos pacientes mais jovens. Dos pacientes com timoma 30 a 50\% são igualmente acometidos de MG.

Os pacientes com timoma geralmente não melhoram após a operação, enquanto $68 \%$ dos que não o apresentam o fazem entre 6 e 24 meses. Aceita-se que os anticorpos antinAchRs sejam produzidos em outros locais além do timo, visto que a timectomia não cura, nem previne $\mathrm{MG}$.

Cerca de $12 \%$ dos portadores de MG têm outra doença autoimune associada.

Estresse, gravidez e infecções são apontados como fatores desencadeantes, enquanto que a anestesia parece não contribuir para o surgimento de MG. 


\section{Incidência}

A prevalência de MG varia de 0,25 a 2 casos por 100 mil indivíduos A MG é mais comum em mulheres jovens (abaixo de 30 anos) e homens em meia-idade, (acima de 50 anos).

\section{Quadro clínico}

A fadiga (fraqueza muscular que piora com o exercício) é a principal característica da doença. Ela surge, na maioria dos casos, nos músculos oculares (diplopia, visão borrada, ptose palpebral), estendendo-se a outros grupamentos musculares, eventualmente comprometendo a deglutição (disfagia) e fonação (disartria) (manifestações denominadas 'bulbares") e a ventilação.

A crise miastênica é definida como rápida instalação de fraqueza muscular culminando em insuficiência respiratória aguda. Ela pode levar ao diagnóstico de MG ou decorrer de posologia inadequada de anticolinesterásicos.

O diagnóstico é confirmado pela resposta ao cloreto de edrofônio (teste do Tensilon $\left.{ }^{\circledR}\right)$. Após a injeção de dose teste (1 a $2 \mathrm{mg}$ ), a administração de $10 \mathrm{mg}$ de edrofônio segue-se de rápida (entre 1 e 5 minutos) melhora da ptose ou da capacidade vital.

\section{Tratamento}

O tratamento com anticolinesterásicos constitui a base do tratamento da MG. Piridostigmina (Mestinon) é administrada até $120 \mathrm{mg}$, a cada 3 horas (30 mg de piridostigmina oral equivalem a $1 \mathrm{mg}$ intravenoso).

Além dos anticolinesterásicos (neostigmina ou piridostigmina), o tratamento de $\mathrm{MG}$ inclui timectomia, imunossupressão inespecífica com corticosteróides, imunoglobulina (IVIg, rituximab [anticorpo monoclonal contra o antígeno CD20 das células B] e outros agentes, como azatioprina $[2,5$ a $3,5 \mathrm{mg} / \mathrm{kg}$ ] ou ciclosporina). A plasmaferese é indicada nas manifestações bulbares graves, nas crises miastênicas ou no preparo pré-operatório dos pacientes não controlados com as medidas anteriormente descritas.

\section{Prognóstico}

Registra-se sobrevida acima de 5 anos de 85 a $90 \%$ tanto em pacientes jovens, como idosos, tratados de crises miastênicas ou portadores de timoma submetidos a timectomia. 


\section{Anestesia e miastenia gravis}

$\mathrm{O}$ anestesiologista assume a atenção de pacientes portadores de MG em diferentes circunstâncias. Nos cuidados pré-, intra e pós-anestésicos (em timectomias ou outras intervenções) e no tratamento da insuficiência respiratória aguda (para assistência ventilatória em crises miastênicas ou colinérgicas).

O pré-operatório do paciente com MG envolve consulta ao neurologista assistente, avaliação da medicação em uso, do impacto do tratamento com imunossupressores, eventual otimização da posologia de anticolinesterásicos (mantidos até o dia da intervenção) ou realização de plasmaferese.

Os testes de função pulmonar fornecem parâmetros úteis para o planejamento do pósoperatório. A ventilação prolongada (acima de 3 horas) é mais provável quando a capacidade vital forçada encontra-se aquém de $40 \mathrm{ml} / \mathrm{kg}$ ou 2,9 litros. A escala de Osserman, destinada a avaliar a intensidade das manifestações clínicas de MG, não guarda correlação consistente com a probabilidade de ventilação artificial prolongada no pós-operatório. Pacientes tratados com $750 \mathrm{mg}$ ou mais de piridostigmina também têm maior risco de dificuldades à desintubação. Aos tratados com corticosteróides adiciona-se o risco de fraqueza muscular induzida por destes agentes.

Estimuladores da motilidade gástrica, como a metoclopramida, e inibidores da secreção ácida, como a ranitidina, são recomendados no pré-operatório, enquanto geralmente os opióides e os diazepínicos são evitados. O uso de bloqueadores neuromusculares no miastênico requer consideração de diversos fatores:

A redução do número de nAchRs traz relativa resistência à ação dos agentes despolarizantes, como a succinilcolina e o mivacúrio. A dose de succinilcolina recomendada para intubação em seqüência rápida em portadores de $\mathrm{MG}$ chega a 1,5 a $2 \mathrm{mg} / \mathrm{kg}$. Por outro lado, o uso crônico de anticolinesterásicos e a plasmaferese diminuem a atividade da butirilcolinesterase, o que prolonga o efeito da succinilcolina e do mivacúrio. O bloqueio tipo fase 2 é mais comum nestes casos.

Com relação ao bloqueio não despolarizante, observa-se na $\mathrm{MG}$ acentuada potencialização da atividade dos agentes desta classe, intensificação de seu efeito, acelerando o início da ação e prolongando sua duração. A ED ${ }_{95}$ do vecurônio reduz-se a 40-55\% do observado em indivíduos normais e a do atracúrio, 58\%. A monitoração com estimulador neuromuscular (train of four) permite titular com segurança os bloqueadores. Em razão da 
ampla variabilidade entre indivíduos, a dose inicial do bloqueadores neuromusculares adespolarizantes é habitualmente reduzida a 1/5 a 1/10 da $\mathrm{ED}_{95}$.

Na condução do bloqueio neuromuscular dá-se preferência ao atracúrio visto dispensar antagonismo com anticolinesterásicos.

O efeito relaxante muscular induzido pelos anestésicos voláteis é acentuado nos portadores de $\mathrm{MG}$, enquanto o comportamento dos barbitúricos, cetamina, propofol e etomidado não é afetado. A depressão respiratória induzida pelos opióides merece atenção particular no paciente miastênico. A anestesia regional pode agravar a fraqueza muscular e deprimir a ventilação em razão do bloqueio motor (sobretudo quando alcança os primeiros segmentos torácicos) e da redução da sensibilidade da membrana pós-juncional determinada pelo anestésico local. Nesse contexto, para intervenções pélvicas ou em extremidades inferiores, a raquianestesia "baixa" reúne as vantagens de mínimo comprometimento dos músculos acessório das ventilação e limitada absorção sistêmica de anestésico local. A anestesia (e analgesia pós-operatória) peridural torácica, combinada com anestesia geral é recomendada em timectomia e outras intervenções realizadas nos segmentos torácicos e abdômen superior.

Antibióticos como os aminoglicosídeos e a polimixinas, mas também as penicilinas, sulfonamidas e tetraciclinas; os antiarrítmicos, como lidocaína, procaína e fenitoína; betabloqueadores e bloqueadores de canais de cálcio podem acentuar a fraqueza muscular da MG e são evitados no peri-operatório.

Alguns aspectos particulares da MG exigem especial atenção no pós-operatório: Ainda que alguns portadores de MG possam exigir entre 24 e 48 horas de ventilação artificial pós-operatória, na maioria dos casos a desintubação é possível ao final das intervenções.

Evita-se antagonizar o bloqueio neuromuscular, aguardando-se a recuperação espontânea. Sugere-se interromper a administração de anticolinesterásicos nas 24 horas seguintes à anestesia, visto este fármaco poder aumentar a produção de secreção nas vias aéreas e dificultar a desintubação, bem como aumentar o risco de fístulas após anastomoses intestinais.

A recuperação da CV (capacidade vital), aferida por sucessivas espirometrias, auxilia na condução da interrupção progressiva da ventilação artificial.

Os acometidos da forma "bulbar" de MG têm elevada probabilidade de aspiração pulmonar durante as crises miastênicas, evidenciada pela incidência de pneumonia em 25 a $33 \%$. 


\section{Referências}

1.Book WJ, Abel M, Eisenkraft JB. Anesthesia and neuromuscular diseases. Anesth Clin North Am 1996;14:515-541.

2.Klinger W, Lehmann-Horn F, Jurkatt-Rott K. Complications of anesthesia in neuromuscular disorders. Neuromuscular Dis 2005; 15:195-206.

3. Naguib M, Lien CA. Pharmacology of muscle relaxants and their antagonists. In Miller D. Miller's Anesthesia. $6^{\text {th }}$ Ed. Elsevier Churchill-Livingstone. Philadelhpia.Ch 13. 2005. p.481-572.

4. Roos KL, Pascuzzi RM. Anesthesia issues in the perioperative management of myasthenia gravis. Seminars in Neurology 2004; 24:83-94. 